\title{
Key Plant, Key Pests: Lilyturf (Liriope muscari) ${ }^{1}$
}

\author{
Juanita Popenoe, Caroline R. Warwick, and David J. Norman²
}

\section{Key Plant: Lilyturf (Liriope muscari)}

Liriope muscari, commonly known as lilyturf, is a large grasslike perennial that is commonly used as a dark-green ground cover or as edging along walks and other areas. During the summer months, the plants shoot out spikes of lilac-purple blooms. Lilyturf is known for its hardiness, and one planting can create a ground cover that will sustain itself for years. Most Lilyturf varieties prefer shade, although 'Evergreen Giant' Lilyturf prefers full sun and will produce thin growth in the shade. These plants grow best in well-drained, moist soils, but the plant is known for its adaptability and will continue growth in less-than-ideal conditions. Lilyturf is common throughout the southern half and coastal areas of the United States, and it does best in USDA Hardiness Zones 6 through 10 (Gilman 2014).

\section{Key Pests: Lilyturf (Liriope muscari)}

This series of Key Plant, Key Pests publications is designed for Florida gardeners, horticulturalists, and landscape professionals to help identify common pests associated with common Florida flora.

This publication provides information and general management recommendations for leaf and crown rot, anthracnose, southern blight, scales, and root rot nematodes. For a more comprehensive guide of woody ornamental insect management, download the current Professional Disease Management Guide for Ornamental Plants, the Integrated Pest Management in the Commercial Ornamental Nursery guide, or the Southeastern US Pest Control Guide for Nursery Crops and Landscape Plantings.

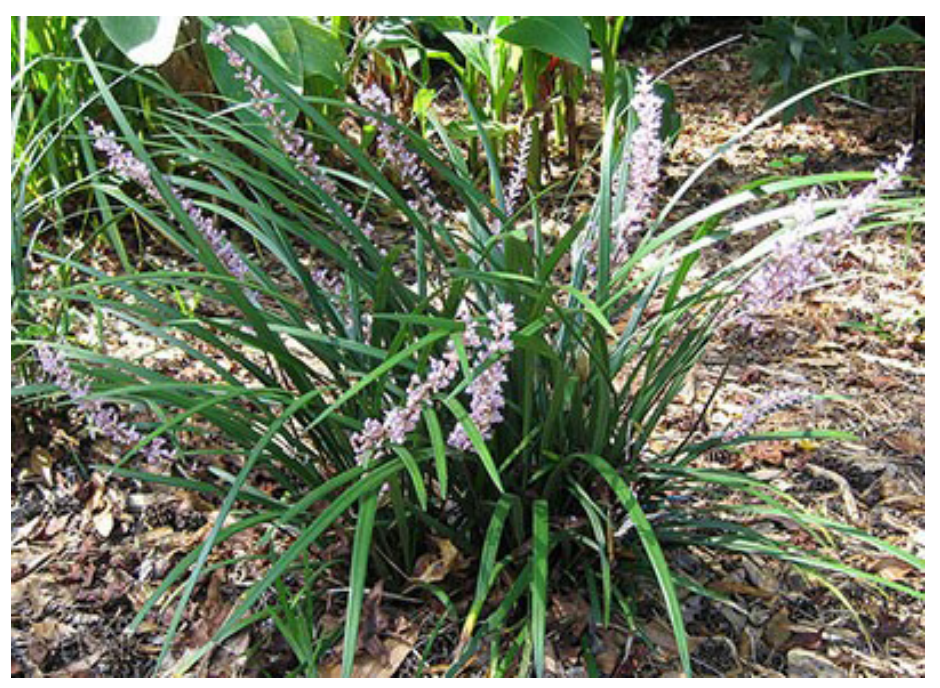

Figure 1. Liriope.

Credits: UF/IFAS Gardening Solutions

1. This document is ENH1336, one of a series of the Environmental Horticulture Department, UF/IFAS Extension. Original publication date March 2021. Visit the EDIS website at https://edis.ifas.ufl.edu for the currently supported version of this publication.

2. Juanita Popenoe, multicounty commercial fruit production agent IV, UF/IFAS Extension Lake County, Tavares, FL; Caroline R. Warwick, science communication specialist; and David J. Norman, professor, Plant Pathology Department, UF/IFAS Extension, Mid-Florida Research and Education Center, Apopka, FL 32703.

Use pesticides safely. Read and follow directions on the manufacturer's label.

The Institute of Food and Agricultural Sciences (IFAS) is an Equal Opportunity Institution authorized to provide research, educational information and other services

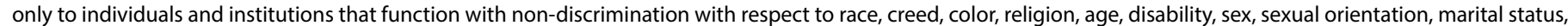

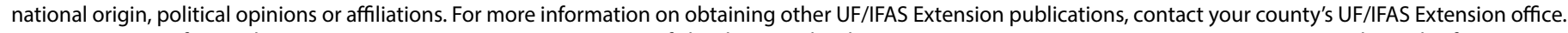
U.S. Department of Agriculture, UF/IFAS Extension Service, University of Florida, IFAS, Florida A \& M University Cooperative Extension Program, and Boards of County Commissioners Cooperating. Nick T. Place, dean for UF/IFAS Extension. 


\section{Leaf and Crown Rot (Phytophthora palmivora)}

\section{RECOGNITION}

Diseased leaves are discolored (yellow) and appear watersoaked, brown, and rotted at the base. Early in disease development, affected leaves develop a pale-green or yellowish cast. Later, the bright-yellow discoloration appears just above the rotted portion and extends slowly upward. Initially the upper portion of the leaf remains green, but eventually, the entire leaf turns yellow and dies. Affected leaves, particularly those in advanced stages of disease development, are easily pulled free from the rhizome or crown. Leaves that are brown or yellowed at the tip but remain green down to the point of attachment are probably affected by other leaf diseases, nutritional problems, or physiological disorders (Leahy and Davidson 1999).

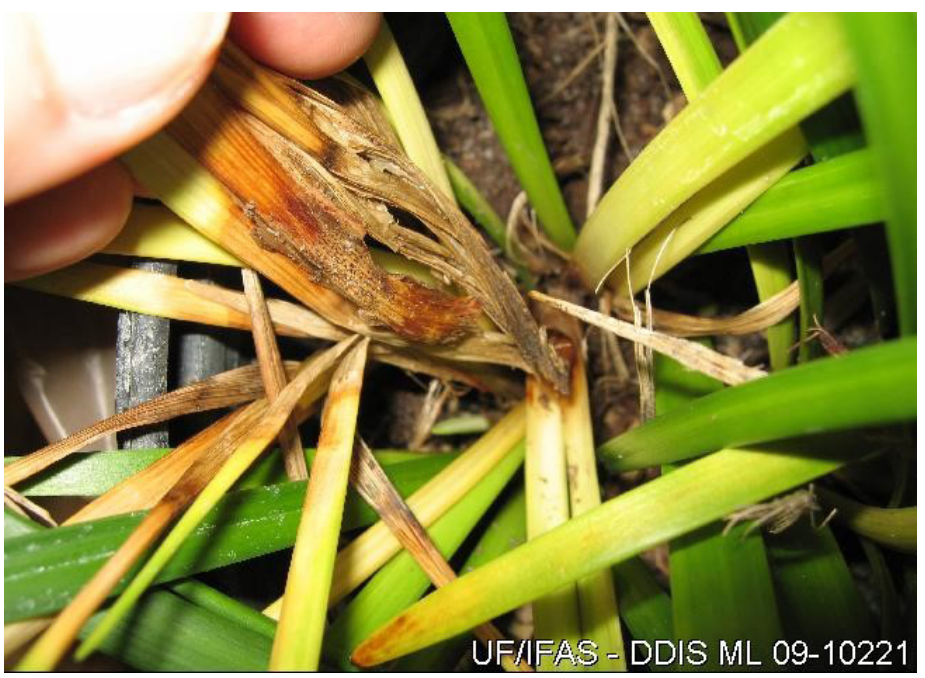

Figure 2. Phythophthora palmivora infestation on lilyturf.

Credits: Juanita Popenoe, UF/IFAS

\section{CONTRIBUTING FACTORS}

Initial disease damage and new infections are more evident in late spring and early summer. Sporangia and zoospores of $P$. palmivora can be easily spread between densely packed container-grown plants produced under overhead sprinkler irrigation or during rainstorms. Both splashing water and surface runoff transport zoospores and sporangia from diseased to nondiseased plants and between plant containers. Disease is also transmitted during propagation; diseased roots and infested soil are transferred to new pots, and wounding involved in division may increase susceptibility. 'Evergreen Giant' is especially susceptible.

\section{MANAGEMENT RECOMMENDATIONS}

Establish and maintain a source of disease-free propagation stock that remains isolated from production sites to exclude or avoid the disease. After discovery of an outbreak, be sure to throw out all infected rootstock and media, disinfecting benches, pots, and other areas in contact with plants or planting material. Phytophthora zoospores accumulate in recycled and/or surface water, which thus should not be used for irrigation. Fungicides such as mefenoxam, fosetyl-aluminum, and certain phosphorous acid-based materials can temporarily prevent disease establishment by inducing or activating natural defense systems within the liriope plant, but these fungicides have little effect on residual inoculum (sporangia) in the soil. Always be sure to check product labels for specific application instructions and species before applying. When such fungicides decompose or are leached from the soil (often within 4 to 6 weeks), disease usually reappears. When choosing potting or planting media, builder's sand was least conducive to infection and disease development, with increases in peat moss content of the media causing increases in disease development. If discovered in the yard, remove and discard the plant.

\section{Anthracnose (Colletotrichum sp.) RECOGNITION}

Patches of reddish speckles will appear typically on leaf tips with a yellow line between the brown and green parts of the leaf. Damage can also appear on the sides of leaves with half-circle patterns.

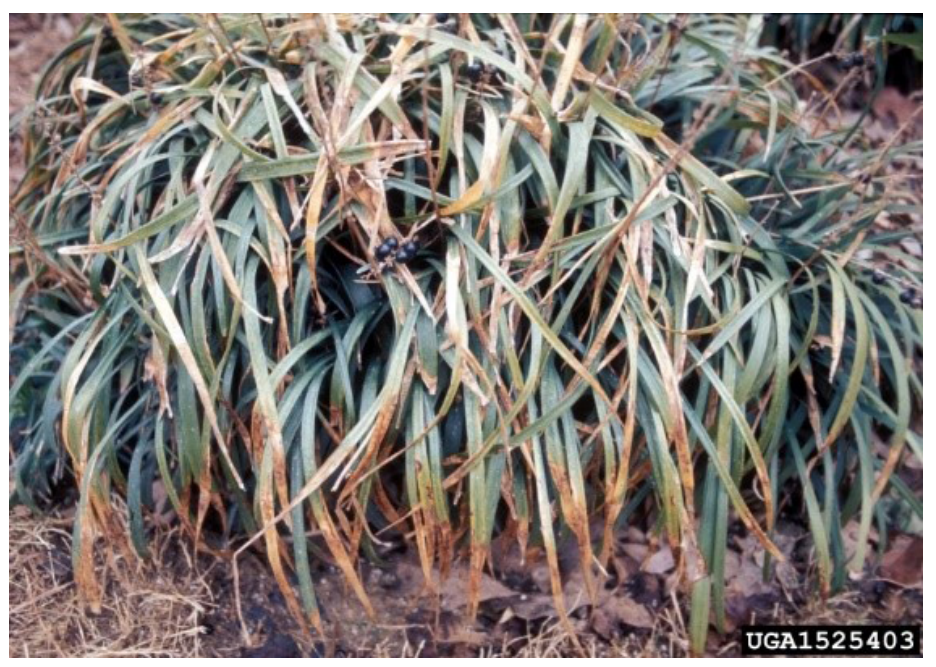

Figure 3. Anthracnose of liriope (Liriope muscari).

Credits: R. K. Jones, North Carolina State University, Bugwood.org

\section{CONTRIBUTING FACTORS}

Colletotrichum requires wet leaves for the spores to germinate and penetrate the leaves directly. Leaf surfaces remaining wet 4 to 6 hours or overnight after an irrigation event or rainstorm is enough to allow germination, as is moisture from dew. When controlling spread, the key is to reduce inoculum and protect new leaves. Generally, this disease 
shows up if liriope has been neglected, not sprayed, and overhead irrigated every day (Russ and Polomski 2019).

\section{MANAGEMENT RECOMMENDATIONS}

Avoid overhead irrigation. Cultural practices to increase air circulation and rapid leaf drying will reduce potential infections. Specific fungicide application recommendations can be found in the UF/IFAS Professional Disease Management Guide for Ornamental Plants.

\section{Root Rots (Fusarium, Rhizoctonia solani) RECOGNITION}

The first symptoms noticed will be a discoloration and then death of the lower leaves as the root system decays and the plant dies from the bottom up. These symptoms may be one-sided on the plant or appear to emerge from a single area.

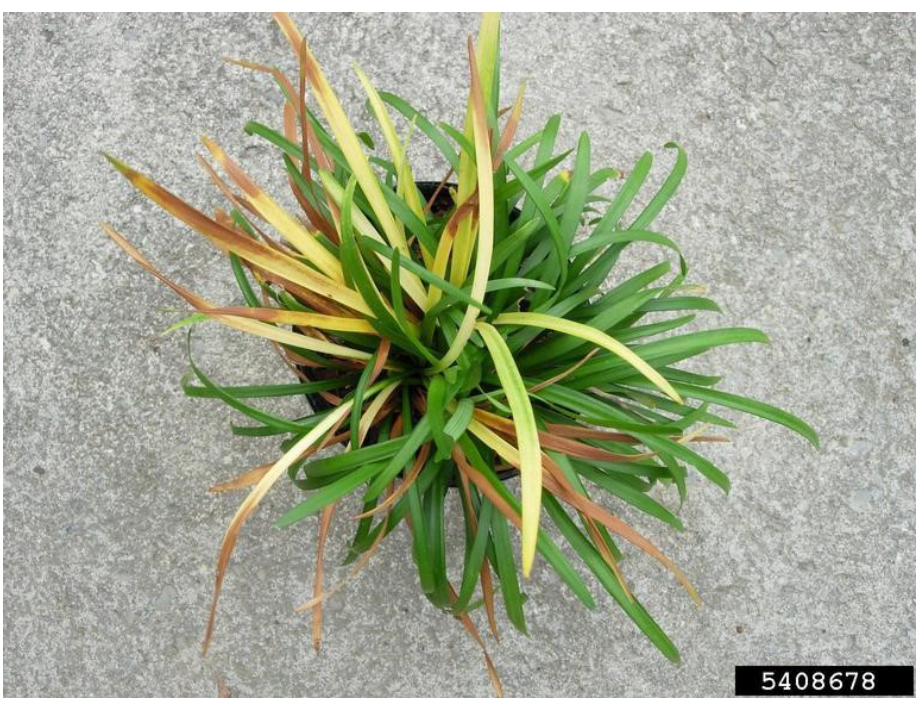

Figure 4. Fusarium damage on liriope.

Credits: Mary Ann Hansen, Virginia Polytechnic Institute and State University, Bugwood.org

\section{CONTRIBUTING FACTORS}

The disease is triggered by periods of excessive soil moisture and warm to hot temperatures. Conditions that favor disease development include planting too deep, poor drainage, shallow rooting, and poor water management.

\section{MANAGEMENT RECOMMENDATIONS}

Manage plants to keep them out of surface water by putting them on raised beds, on ground cloth, or in well-drained soil. Reduce irrigation during rainy periods. Fungicides can be used preventatively at potting but are not much use after symptoms are noticed, because the root system will be significantly rotted before leaf symptoms are seen. Check roots of nursery-grown plants before planting into the landscape.

\section{Southern Blight (Sclerotinium rolfsii) RECOGNITION}

Affected plants will first be noticed to wilt, and a soft brown rot at the soil line is visible. A white cottony mycelium embedded with tiny white to orange sclerotia (very small balls of spores) can be seen upon close examination.

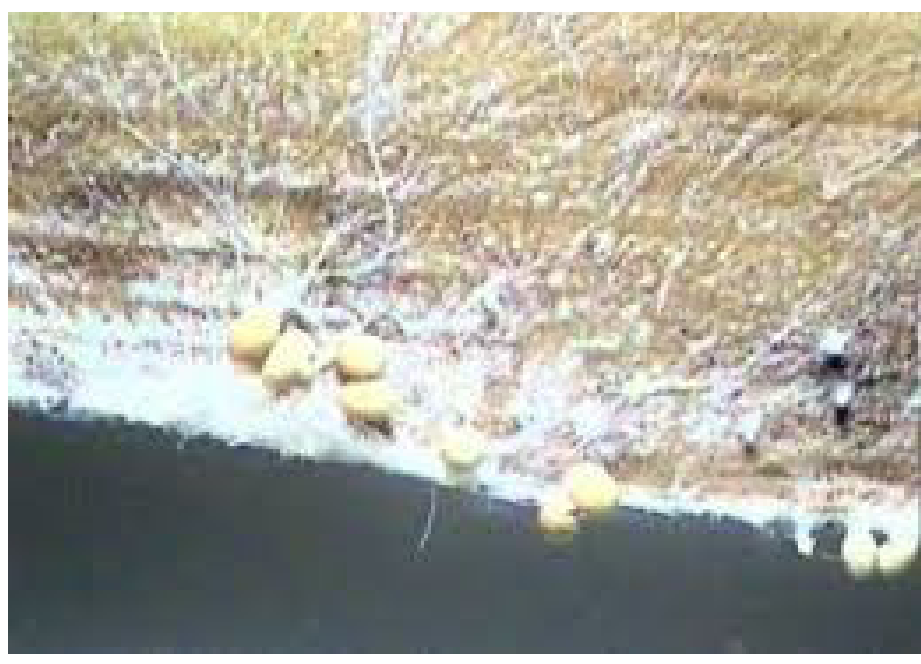

Figure 5. Note the tiny brown sclerotia found at the base of the plant. Credits: Juanita Popenoe, UF/IFAS

\section{CONTRIBUTING FACTORS}

The fungus is spread by running water, infested soil, tools, and infected plants, and it can survive in the soil indefinitely. Be sure to properly clean and sanitize any tools or materials after finding an infestation.

\section{MANAGEMENT RECOMMENDATIONS}

Start with clean soil, and remove and destroy diseased plants. Chemical treatments may help prevent the disease but will not eliminate the fungus. Specific fungicide application recommendations can be found in the UF/IFAS Professional Disease Management Guide for Ornamental Plants.

\section{Scale (Six Species, Fern and Proteus Most Common) \\ RECOGNITION}

Scales cause damage by sucking the juices from the plant. Feeding on the leaf undersides may cause yellow spots to appear on the upper leaf surfaces, which become larger as the scales continue to feed. Scale feeding may result in leaf drop and reduced growth. Mature scales are visible, although sometimes they are well hidden in crevices. Immatures, or crawlers, are tiny and require a hand lens to detect. The presence of sooty mold is also associated with soft scales. The fern scale has brown female scales and white males (Futch, McCoy, and Childers 2018). 


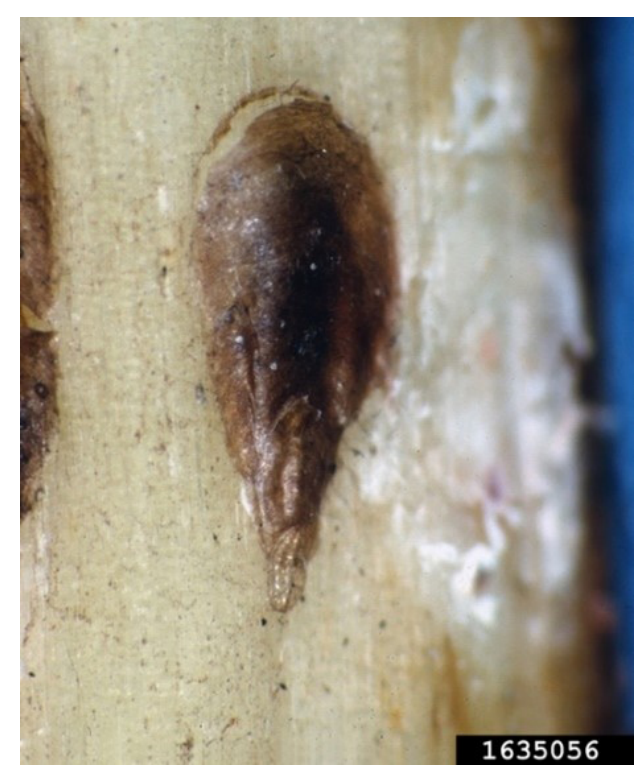

Figure 6. Fern scale insects (Pinnaspis aspidistrae) on liriope. Credits: John A. Davidson, University of Maryland, College Park, Bugwood.org

\section{CONTRIBUTING FACTORS}

Mature scales are present year-round, but crawlers hatch in spring and throughout the warm season, depending on species.

\section{MANAGEMENT RECOMMENDATIONS}

Round holes in the scale bodies indicate parasitic wasps have emerged and are helping control the pest population. Use oils or approved insecticides if parasitism is insufficient and the problem warrants. Dead scales, however, will remain on the plant. You need to squish the scale to determine if it is dry and dead underneath. Also, dead scales may still cover live eggs that will hatch and reinfest. Contact insecticides should be timed to control crawlers, because matures are well-protected by a waxy covering. Control of adult scales is especially difficult because the shell-like covering protects these pests from exposure to the pesticide. In these cases, chemicals that are systemic (within the plant) are more effective than chemicals that are toxic only when in actual contact with the pest.

\section{Root-Knot Nematodes RECOGNITION}

Poor growth, plant decline, yellowing leaves, and thinning of the canopy may be symptoms of nematode infestation. Infected roots have obvious galls and may be brown and stunted (UF/IFAS Gardening Solutions 2018).

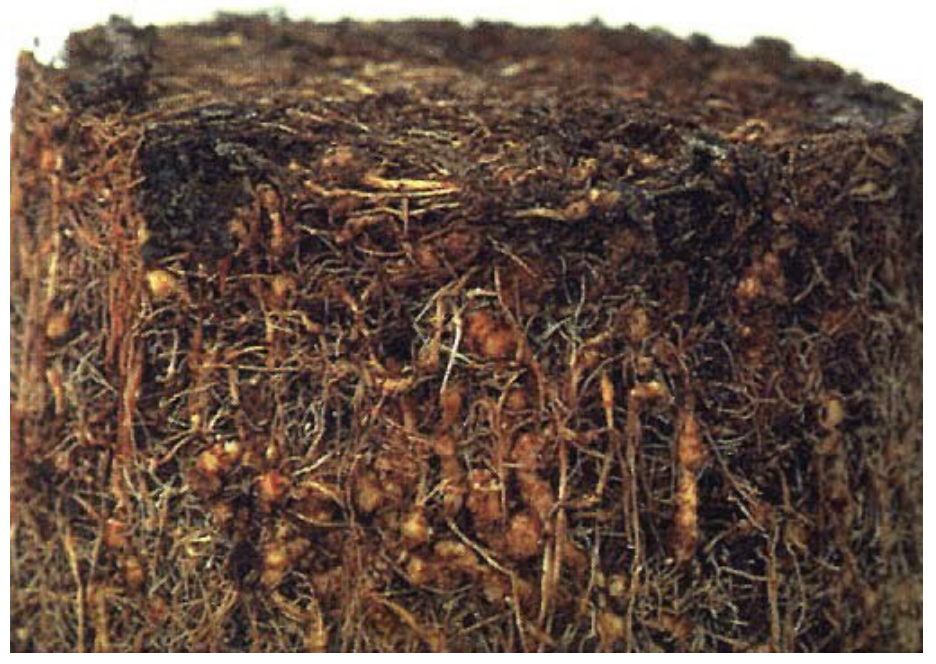

Figure 7. Root-knot nematode damage. Credits: Juanita Popenoe, UF/IFAS

\section{CONTRIBUTING FACTORS}

The highest populations of nematodes occur in welldrained sandy soils where previous crops have supported high levels of nematodes.

\section{MANAGEMENT RECOMMENDATIONS}

Keep plants as healthy as possible with adequate water and fertilizer to support new roots. No chemical controls are available for use on existing plants. When replacing plants, remove all roots and replace soil. Avoid replanting with susceptible species or fumigate before replanting.

\section{References}

Futch, S. H., C. W. McCoy, and C. C. Childers. 2018. "A Guide to Scale Insect Identification.” EDIS 2001 (4). https:// edis.ifas.ufl.edu/ch195

Gilman, E. F. 2014. “Liriope muscari 'Evergreen Giant' Evergreen Giant Lilyturf.” EDIS 1999 (5). https://edis.ifas. ufl.edu/fp348

Leahy, R. M., and D. A. Davidson. 1999. Leaf and Crown Rot of Liriope muscari. Plant Pathology Circular No. 392. Gainesville: Florida Department of Agriculture and Consumer Services, Division of Plant Industry. https://www. fdacs.gov/content/download/11398/file/pp392.pdf

Russ, K., and B. Polomski. 2019. Liriope. HGIC 1108. Clemson, SC: Clemson Cooperative Extension Home and Garden Information Center. https://hgic.clemson.edu/ factsheet/liriope/

UF/IFAS Gardening Solutions. 2018. "Nematodes.” https:// gardeningsolutions.ifas.ufl.edu/care/pests-and-diseases/ pests/nematodes.html 